Eur. J. Clin. Chem. Clin. Biochem.

Vol. 31, 1993, pp. 97-101

(C) 1993 Walter de Gruyter \& Co. Berlin - New York

\title{
Measurement of Water Turnover Using a Stable Isotope Technique: Calculation of Error Propagation
}

\author{
By C. Fusch ${ }^{1}$ and H. Moeller ${ }^{2}$ \\ 1 Abteilung für Neonatologie, Universitäts-Frauenspital, Bern, Schweiz \\ 2 Universitäts-Kinderklinik Tübingen, Germany
}

(Received April 14/August 26, 1992)

\begin{abstract}
Summary: Water turnover may be determined with stable isotope techniques from the product of tracer dilution space and tracer elimination rate. Tracer concentrations must be measured in two body fluid samples which are separated by a sampling interval. The tracer concentration of the first sample may be charged with an error which may be due to analytical errors, incomplete tracer dilution or because the necessary steadystate assumption (water influx equals water efflux) is violated at the moment of tracer loading. Error propagation shows that the influence of this error on the estimation of water turnover is partially compensated for. The goodness of compensation depends on the sampling interval and on the magnitude of the error of the first sample. The error is best compensated using sampling intervals of 1.5 tracer half lifes.
\end{abstract}

\section{Introduction}

A non-invasive, stable isotope method may be used for the measurement of water turnover in humans and animals (1-4). After a tracer dose of ${ }^{2} \mathrm{H}_{2} \mathrm{O}$ (usually $0.1-1.5 \mathrm{ml} / \mathrm{kg}$ body weight) is distributed in body water, the tracer is eliminated from body water following a first-order kinetic. Water turnover is calculated from the product of ${ }^{2} \mathrm{H}_{2} \mathrm{O}$ distribution space and ${ }^{2} \mathrm{H}_{2} \mathrm{O}$ elimination rate. The distribution space is calculated from the ${ }^{2} \mathrm{H}_{2} \mathrm{O}$ concentration in a body fluid sample obtained some hours after ${ }^{2} \mathrm{H}_{2} \mathrm{O}$ application. The elimination rate is calculated from the semilog linear ${ }^{2} \mathrm{H}_{2} \mathrm{O}$ decrease which occurs after distribution is completed. It has been shown that the elimination rate may be reliably calculated using either multiple or two datapoints (5).

Recently, we performed a field study on 171 healthy infants in which we measured water turnover under normal conditions at home (6). ${ }^{2} \mathrm{H}_{2} \mathrm{O}$ concentrations were measured using a previously described method (7). We calculated the tracer elimination rate by the two-point method. A first urine sample was obtained between 2 and 3 hours after an oral load of ${ }^{2} \mathrm{H}_{2} \mathrm{O}$, the second sample was obtained after sleep in the morning of day 5 for children below one year and of day 10 for older children. The published times for equilibration of an oral load of ${ }^{2} \mathrm{H}_{2} \mathrm{O}$ into body water, especially into urine, vary from 1.5 to 6 hours $(7-12)$. ${ }^{2} \mathrm{H}_{2} \mathrm{O}$ equilibration times for healthy children have not been published. The field study character of the published investigation required that the post-dose sampling interval should not be longer than three hours. Therefore, the ${ }^{2} \mathrm{H}_{2} \mathrm{O}$ concentration of the first sample may be charged with a systematic error, and the water turnover may therefore not have been correctly measured.

This problem could be solved by establishing ${ }^{2} \mathrm{H}_{2} \mathrm{O}$ equilibration times in children, but - for ethical reasons - such a study cannot be performed in healthy infants and children when the ${ }^{2} \mathrm{H}_{2} \mathrm{O}$ plasma concentration is used as the internal reference. Alternatively, the effect of this error on the estimation of water turnover may be evaluated by calculating the error propagation in cases where the first sample is charged with an error. Moreover, error may occur in the first sample for other reasons: the steady-state condition of a constant distribution volume may be not fulfilled, e.g. water influx may differ from water 
efflux on the day the measurement of water turnover was started, or an error may occur during the measurement of ${ }^{2} \mathrm{H}_{2} \mathrm{O}$ concentrations. Therefore, we think that the calculation of error propagation, as presented in this paper, may be of basic interest.

\section{Theory and Methods}

The test dose of ${ }^{2} \mathrm{H}_{2} \mathrm{O}$ is given at the time $\mathrm{t}_{0}$. The first sample is obtained at time $t_{1}$ (after distribution in body water) and the second sample at time $t_{2}$. Water turnover $\left(R_{\mathrm{H}_{2} \mathrm{O}}\right)$ is calculated from the product of ${ }^{2} \mathrm{H}_{2} \mathrm{O}$ distribution space (total body-water, TBW) and ${ }^{2} \mathrm{H}_{2} \mathrm{O}$ elimination rate $\left(\mathrm{k}_{1}\right)$ :

$$
\mathrm{R}_{\mathrm{H}_{2} \mathrm{O}}=\mathrm{TBW} \cdot \mathbf{k}_{1}
$$

where

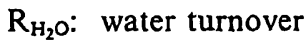

TBW: total body, water,

$\mathrm{k}_{1}$ : elimination constant of ${ }^{2} \mathrm{H}_{2} \mathrm{O}$ from TBW.

Total body water (TBW) and $k_{1}$ are calculated according to

$$
\mathrm{TBW}=\frac{\mathrm{V}_{0}}{\Delta c_{1}}
$$

and

$$
\mathrm{k}_{1}=\frac{\ln \Delta c_{1}-\ln \Delta c_{2}}{\Delta \mathrm{t}}
$$

where

$\mathrm{V}_{0}$ : applied volume of ${ }^{2} \mathrm{H}_{2} \mathrm{O}$,

$\Delta \mathrm{t}$ : sample time interval, $t_{2}-t_{1}$

$\Delta c_{1}$ : ${ }^{2} \mathrm{H}_{2} \mathrm{O}$ concentration above natural abundance at time $\mathrm{t}_{1}$ $\Delta c_{2}:{ }^{2} \mathrm{H}_{2} \mathrm{O}$ concentration above natural abundance at time $\mathrm{t}_{2}$.

The combination of equations (2) and (3) gives:

$$
\mathrm{R}_{\mathrm{H}_{2} \mathrm{O}}=\frac{\mathrm{V}_{0}}{\Delta \mathrm{t}} \cdot \frac{\ln \left(\Delta c_{1} / \Delta c_{2}\right)}{\Delta c_{1}}
$$

The value of $\Delta c_{1}$ may be charged with an error $\mathrm{x} \cdot \Delta c_{1}$ which may be due to analytical imperfections or to the fact that the sample has been drawn before ${ }^{2} \mathrm{H}_{2} \mathrm{O}$ equilibration was completed. We get for the estimate $\mathrm{R}_{\mathrm{H}_{2}} \mathrm{O}$ * of water turnover

$$
\mathrm{R}_{\mathrm{H}_{2} \mathrm{O}}{ }^{*}=\frac{\mathrm{V}_{0}}{\Delta \mathrm{t}} \cdot \frac{\ln \left[\Delta c_{1} \cdot(1+\mathrm{x}) / \Delta c_{2}\right]}{\Delta c_{1} \cdot(1+\mathrm{x})}
$$

The error for the estimation of water turnover may then be calculated as

$$
\frac{\mathrm{R}_{\mathrm{H}_{2} \mathrm{O}}}{\mathrm{R}_{\mathrm{H}_{2} \mathrm{O}}}=\frac{\ln \left(\Delta c_{1} / \Delta c_{2}\right)+\ln (1+\mathrm{x})}{\ln \left(\Delta c_{1} / \Delta c_{2}\right) \cdot(1+\mathrm{x})}
$$

Replacing the constant term $\ln \left(\Delta c_{1} / \Delta c_{2}\right)$ by $\mathrm{k}$, we get:

$$
\frac{\mathrm{R}_{\mathrm{H}_{2} \mathrm{O}}}{\mathrm{R}_{\mathrm{H}_{2} \mathrm{O}}}=\frac{k+\ln (1+\mathrm{x})}{\mathrm{k} \cdot(1+\mathrm{x})}
$$

The relative error $F$ of the measurement of water turnover is defined as

$$
F=\frac{R_{\mathrm{H}_{2} \mathrm{O}} *-R_{\mathrm{H}_{2} \mathrm{O}}}{R_{\mathrm{H}_{2} \mathrm{O}}}
$$

which is

$$
F=\frac{\ln (1+x)-k x}{k(1+x)}
$$

According to Taylor series deconvolution, the term $\ln (1+x)$ may be replaced by $\mathrm{x}$ for small values of $\mathrm{x}$. We obtain for the relative error $F$ of the estimation of water turnover

$$
F=\frac{x-k x}{k+k x}
$$

The error $x$ with which the ${ }^{2} \mathrm{H}_{2} \mathrm{O}$ concentration of the first sample is charged, appears in the numerator as well as in the denominator of equations (9) and (10). From equation (10), it can easily be seen that the influence of $x$ on the estimation of water turnover is partially compensated for. The degree of compensation depends on the values of $\mathrm{k}$ and $\mathrm{x}$.

Taking equation (9), we calculated the error $F$ for the measurement of water turnover. The error of the first sample is varied in the range of $\pm 20 \%$, which is a larger range than should occur in reality. Additionally, we varied the sampling interval from 1 to 3 half lifes, in order to find the sampling interval which is most robust against the error of the first sample.

Using experimental data,we calculated for two cases of identical water turnover, but different sampling intervals, how an error of the first sample influences the measurement of water turnover, if the steady-state condition of distribution space is not fulfilled (10 year old child, $31 \mathrm{~kg}, 1.54 \mathrm{ml}^{2} \mathrm{H}_{2} \mathrm{O} / \mathrm{kg}$ body weight, $c_{1}=0.00256$ volume fraction, natural ${ }^{2} \mathrm{H}_{2} \mathrm{O}$ abundance: 0.00015 volume fraction). In the first case, it is assumed that $\Delta c_{1} / \Delta c_{2}$ is 2.2 (corresponding to 1.1 tracer half lifes) with a ${ }^{2} \mathrm{H}_{2} \mathrm{O}$ concentration of the second sample of 0.00125 volume fraction after a sampling interval $\Delta t$ of 231.5 hours. In the second case $\Delta c_{1} / \Delta c_{2}$ is 6.0 (corresponding to 2.6 tracer half lifes) with a ${ }^{2} \mathrm{H}_{2} \mathrm{O}$ concentration of the second sample of 0.00055 volume fraction obtained after $\Delta \mathrm{t}=530.0$ hours. It must be emphasized that the rate of water turnover is identical for both cases and only the sampling interval is varied. De- and hyperhydration up to $\pm 10 \%$ of total body water are assumed during the moment of the first ${ }^{2} \mathrm{H}_{2} \mathrm{O}$ load.

\section{Results}

\section{Discussion of equation (9)}

In figure 1, the error $F$ of the estimation of water turnover is plotted in relation to the error $\mathrm{x}$ of the first sample. The graphs $a-f$ were established for ratios $\mathrm{k}$ of $\Delta c_{1} / \Delta c_{2}$ ranging from 2.0 to 8.0 . These ratios correspond to sampling intervals of 1.0 to 3.0 tracer half lifes. The graph $\mathrm{g}$ is the line of identity which is obtained if the error of the first sample is not compensated for $(F=x)$. In general, no graph touches the line of identity. This proves that the influence of the erroneous first sample on water turn= over is partially compensated for under all the assumed conditions. If the ratio of $\mathrm{k}$ is between 2.5 and 3.0 , the error $x$ is nearly eliminated (between 75 and $95 \%$ ). Ratios of 2.5 and 3 correspond to sampling intervals of 1.3 and 1.6 tracer half lifes, respectively. For shorter sampling intervals, the error is less com- 


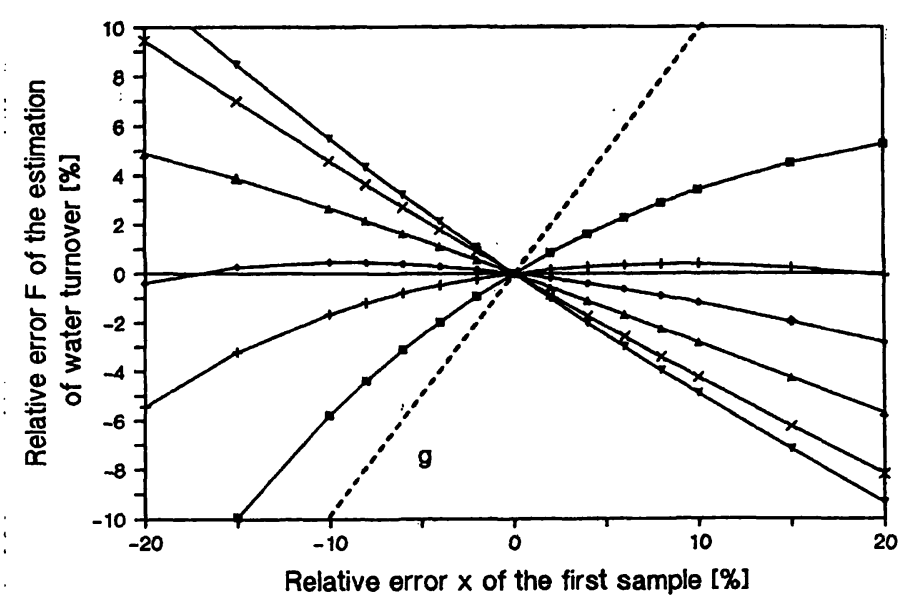

Fig. 1. Influence of the error $x$ of the ${ }^{2} \mathrm{H}_{2} \mathrm{O}$ concentration of the first sample on the estimation of water turnover. The ratio $\Delta c_{1} / \Delta c_{2}$ is assumed to be 2.0, 2.5, 3.0, 4.0, 6.0, and 8.0 (graph $\mathrm{a}-\mathrm{f}$ ). This ratio corresponds to sampling intervals of 1.0,1.3, 1.6, 2.0, 2.6 and 3.0 tracer half lifes. The graph $\mathrm{g}$ is the graph of identity which is obtained if the effect of error $x$ of the first sample on the error $F$ of water turnover is not compensated for $(F=x)$.

pensated (less than $50 \%$ ). For longer sampling intervals, underestimation of the first ${ }^{2} \mathrm{H}_{2} \mathrm{O}$ concentration turns into an overestimation of water turnover and vice versa (compensation between 40 and $75 \%$ ).

\section{Calculating using real data}

Table 1 shows data for the ${ }^{2} \mathrm{H}_{2} \mathrm{O}$ concentration of the first sample, elimination constant $\mathrm{k}_{1}$, water turnover, and the errors $\mathrm{x}$ and $\mathrm{F}$ for the first sample and water turnover, respectively, using experimental data. It can be seen that the error $\mathrm{x}$ of the first sample is partially compensated for. The error $F$ of water turnover is smaller than the error $\mathrm{x}$, but it can be seen that the degree of compensation depends on the ratio $\Delta c_{1} / \Delta c_{2}$ which is closely correlated to the sampling interval.

\section{Discussion}

From the calculations of error propagation presented a in this paper it can be seen that water turnover may be measured, even if the ${ }^{2} \mathrm{H}_{2} \mathrm{O}$ concentration of the first sample is charged with an error. This beneficial effect is due to the fact that the ${ }^{2} \mathrm{H}_{2} \mathrm{O}$ concentration of the first sample is used either to calculate distribution volume (total body water, TBW) and the elimination rate $\left(\mathrm{k}_{1}\right)$ and that the product of both yields water turnover $\left(\mathrm{R}_{\mathrm{H}_{2} \mathrm{O}}\right)$. An overestimation of $\Delta c_{1}$ causes an underestimation of total body water (TBW), but at the same time an overestimation of the elimination rate. We showed that the error of the first sample is compensated over a wide range (relative error of $\pm 20 \%$ ) if the sampling interval is close to 1.5 tracer half lifes. But even for longer or shorter sampling intervals, the error $\mathrm{x}$ may be compensated, although to a lesser extent. The error of the ${ }^{2} \mathrm{H}_{2} \mathrm{O}$ concentration of the first sample may occur for several reasons: even if ${ }^{2} \mathrm{H}_{2} \mathrm{O}$ has correctly equilibrated within the body water (published data about the interval required for equilibration are not identical $(7-12)$ ). and even if the method of ${ }^{2} \mathrm{H}_{2} \mathrm{O}$ analysis has a small error, there may be a violation of the assumption of steady-state (a certain percentage day-to-day variation of body water in healthy subjects). Therefore, we would like to suggest the use of sampling intervals close to 1.5 tracer half lifes in order to maximize the precision of the measurement of water turnover.

In our study on the water turnover of healthy children (6), the worst-case error of the ${ }^{2} \mathrm{H}_{2} \mathrm{O}$ concentration of the first sample due to incomplete ${ }^{2} \mathrm{H}_{2} \mathrm{O}$ distribution is $6 \%(8)$. As we used sampling intervals close to 1.5 tracer half lifes, we must conclude that water turnover is measured in this study with an error of less than $2 \%$, an error which should be acceptable for a field study.

Tab. 1. Evaluation of the influence of the error $x$ of the first sample using experimental data applied to two different sampling intervals, assuming the same value for the water turnover $(1.611 \mathrm{l} / \mathrm{d}): 10$ year old child, $31 \mathrm{~kg}, 1.54 \mathrm{ml}{ }^{2} \mathrm{H}_{2} \mathrm{O} / \mathrm{kg}$ body weight, natural abundance of ${ }^{2} \mathrm{H}_{2} \mathrm{O}: 0.00015$ volume fraction, ${ }^{2} \mathrm{H}_{2} \mathrm{O}$ concentration 3 hours after oral load $\left(\Delta c_{1}\right): 0.00256$ volume fraction, $1^{\text {st }}$ case: ${ }^{2} \mathrm{H}_{2} \mathrm{O}$ concentration after 231.5 hours $\left(\Delta c_{2}\right): 0.00125$ volume fraction, $2^{\text {nd }}$ case: ${ }^{2} \mathrm{H}_{2} \mathrm{O}$ concentration after 530.0 hours $\left(\Delta c_{2}\right): 0.00055$ volume fraction. The steady-state condition (water influx = water efflux) is not fulfilled, because hyper- or dehydration up to $10 \%$ of body water is assumed; this is corrected during the investigation.

\begin{tabular}{|c|c|c|c|c|c|c|c|c|c|c|}
\hline \multirow[b]{2}{*}{$\Delta c_{1} / \Delta c_{2}$} & \multirow[b]{2}{*}{$\cdot$} & \multirow{2}{*}{$\begin{array}{l}\text { Total } \\
\text { body } \\
\text { water } \\
\text { TBW [1] }\end{array}$} & \multirow{2}{*}{$\begin{array}{l}\text { Apparent } \\
\Delta c_{1}{ }^{*} \\
\text { [volume } \\
\text { fraction] }\end{array}$} & \multicolumn{2}{|c|}{$\begin{array}{l}\text { Elimination } \\
\text { constant }\left[\mathrm{d}^{-1}\right]\end{array}$} & \multicolumn{2}{|c|}{$\begin{array}{l}\text { Water turnover } \\
\mathrm{R}_{\mathrm{H}_{2} \mathrm{O}}[\mathrm{l} / \mathrm{d}]\end{array}$} & \multirow[t]{2}{*}{$\begin{array}{l}\text { Error } x \\
1^{\text {st }} \text { sample } \\
{[\%]}\end{array}$} & \multicolumn{2}{|c|}{$\begin{array}{l}\text { Error } \mathrm{F} \text { of } \mathrm{R}_{\mathrm{H}_{2} \mathrm{O}} \\
{[\%]}\end{array}$} \\
\hline & & & & 2.2 & 6.0 & 2.2 & 6.0 & & 2.2 & 6.0 \\
\hline $\begin{array}{l}\text { Dehydration } \\
{[\% \text { of TBW] }}\end{array}$ & $\begin{array}{r}10 \\
5\end{array}$ & $\begin{array}{l}17.83 \\
18.82\end{array}$ & $\begin{array}{l}0: 00283 \\
0.00269\end{array}$ & $\begin{array}{l}0.0922 \\
0.0866\end{array}$ & $\begin{array}{l}0.0862 \\
0.0838\end{array}$ & $\begin{array}{l}1.644 \\
1.630\end{array}$ & $\begin{array}{l}1.535 \\
1.574\end{array}$ & $\begin{array}{r}10.5 \\
5.0\end{array}$ & $\begin{array}{l}2.1 \\
1.2\end{array}$ & $\begin{array}{l}-4.7 \\
-2.3\end{array}$ \\
\hline Normohydration & & $19: 81$ & 0.00256 & 0.0814 & 0.0814 & 1.611 & 1.611 & 0.0 & 0.0 & 0.0 \\
\hline $\begin{array}{l}\text { Hyperhydration } \\
{[\% \text { of } \mathrm{TBW}]}\end{array}$ & $\begin{array}{r}5 \\
10\end{array}$ & $\begin{array}{l}20.80 \\
21.79\end{array}$ & $\begin{array}{l}0.00245 \\
0: 00234\end{array}$ & $\begin{array}{l}0.0763 \\
0.0715\end{array}$ & $\begin{array}{l}0.0792 \\
0.0770\end{array}$ & $\begin{array}{l}1.586 \\
1.556\end{array}$ & $\begin{array}{l}1.646 \\
1.678\end{array}$ & $\begin{array}{l}-4.5 \\
-8.6\end{array}$ & $\begin{array}{l}-1.5 \\
-3.4\end{array}$ & $\begin{array}{l}2.1 \\
4.2\end{array}$ \\
\hline
\end{tabular}




\section{Appendix}

During the review process, four questions have been asked which may be of basic interest. On request of the Editor in Chief, these questions as well as our answers are added in this chapter.

Question 1: Are two sample points adequate to yield correct estimates for a first order kinetic?

Answer: The gold standard for the estimation of the elimination constant $k_{1}$ is the non-linear regression using a data set of daily ${ }^{2} \mathrm{H}$ concentrations during an interval of two tracer half lives without violation of the steady state condition of a totally constant body water pool. This may be hardly performed in a practical trial, especially during a pediatric field study. It has been previously shown that turnover rates may be reliably calculated from the tracer decay if only two data points are available (5). We would like to illustrate this using original data for ${ }^{18} \mathrm{O}$ elimination kindly placed at our disposal by Dr. $S$. Welle.

The semilogarithmic decay of the tracer concentration during the first 14 days of application is shown in figure 2. The tracer concentration decreases linearly, which confirms our assumed model of first order kinetics. Figure 3 shows the 13 elimination constants $k_{1}$ as calculated using the tracer decay from the first

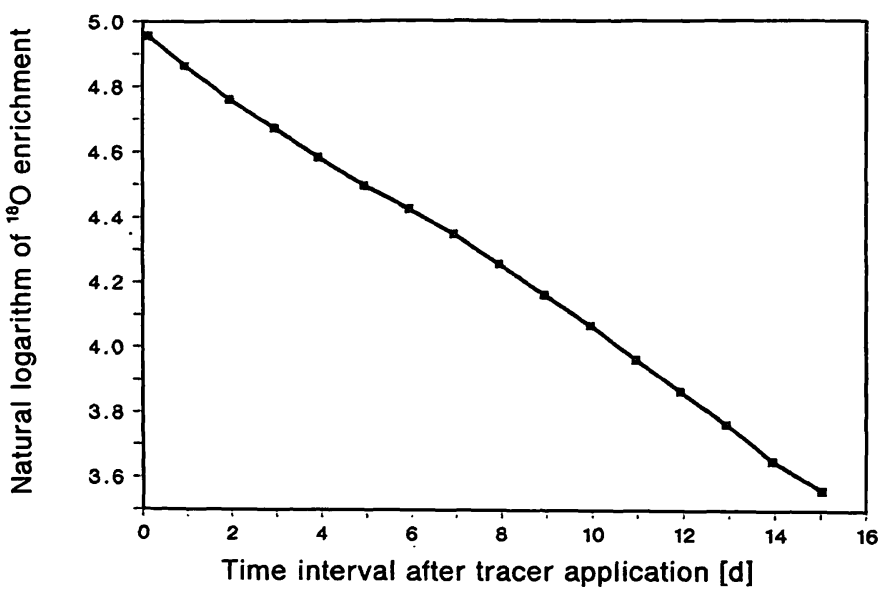

Fig. 2. Semilogarithmic plot of the ${ }^{18} \mathrm{O}$ concentrations in urine after an oral load of ${ }^{2} \mathrm{H}_{2}{ }^{18} \mathrm{O}$.

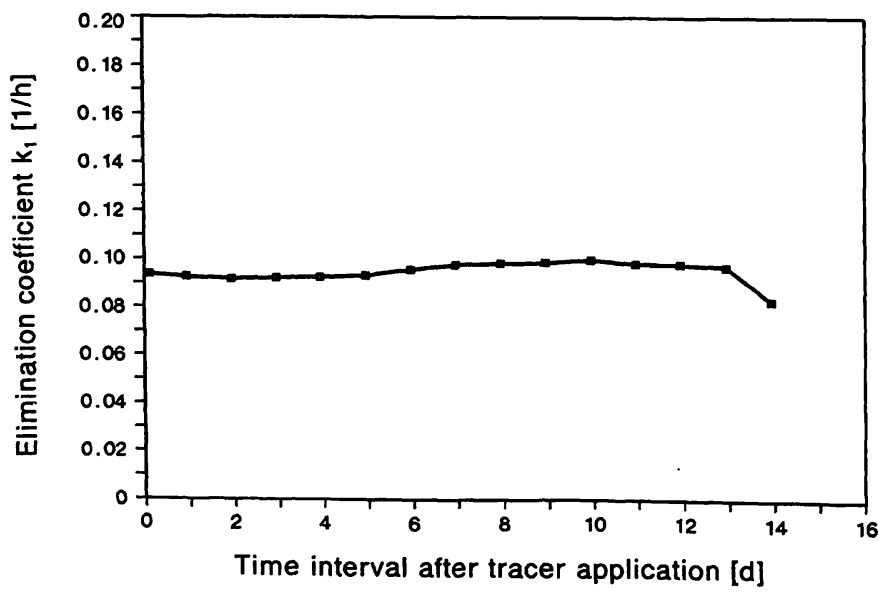

Fig. 3. Plot of the 13 elimination constants $\left(k_{1}\right)$ calculated using the tracer decay between the first post-dose sample on day 0 and samples obtained on post-dose days $1,2,3$ until 14. post-dose sample on day 0 to samples obtained on post-dose days $1,2,3$ until 14 . It can be seen that $k_{1}$ may be reliably and precisely measured using only two data points.

Question 2: If $\mathrm{k}$ is assumed to be $1, \dot{\mathrm{F}}^{\prime}$ must be 0 for all values of the error of the first sample. In equation (7), the constant $k$ is denoted as $\mathrm{k}=\ln \left(\Delta c_{1} / \Delta c_{2}\right)$. The constant $\mathrm{k}$ may also be obtained from $k=k_{1} \Delta t$ where $\Delta t=t_{2}-t_{1}$ according to equation (3). As a consequence, the relative error F may be reduced to 0 for all values of $\mathrm{x}$ by simply choosing a sampling interval of $\Delta t=1 / k_{1}$.

Answer: This result which is described for the special case $\Delta t=1 / k_{1}$ may also be obtained if equation (4) is considered. We would like to delineate the following:

$$
\begin{array}{ll}
\Delta c_{1}=\mathrm{Y}_{0} \mathrm{e}^{-k_{1} t_{1}} & \text { with } \mathrm{t}_{1}=0 \\
\Delta c_{2}=\mathrm{Y}_{0} \mathrm{e}^{-k_{1} t_{2}} & \text { with } \mathrm{t}_{2}=1 / \mathrm{k}_{1}
\end{array}
$$

This leads to

$$
\Delta c_{1}=\mathrm{Y}_{0} \text { and } \Delta c_{2}=\mathrm{Y}_{0} \cdot \mathrm{e}^{-1}
$$

Combining both equations of (11) yields

$$
\Delta c_{1} / \Delta c_{2}=\mathrm{e}^{1} \text { or } \ln \left(\Delta c_{1} / \Delta c_{2}\right)=1
$$

Using equations (11) and (12), equation (4) may be written as

$$
\mathrm{R}_{\mathrm{H}_{2} \mathrm{O}}=\frac{\mathrm{V}_{0}}{\Delta \mathrm{t}} \cdot \frac{1+\ln (1+\mathrm{x})}{\mathrm{Y}_{0}(1+\mathrm{x})}
$$

Using the approximation $\ln (1+x)=x$ we find

$$
\mathrm{R}_{\mathrm{H}_{2} \mathrm{O}}=\frac{\mathrm{V}_{0}}{\Delta \mathrm{t}} \cdot \frac{1}{\mathrm{Y}_{0}}
$$

which is the well-known equation

$$
\mathrm{R}_{\mathrm{H}_{2} \mathrm{O}}=\mathrm{TBW} \cdot \mathrm{k}_{1}
$$

where $\mathrm{TBW}=\mathrm{V}_{0} / \mathrm{Y}_{0}$ and $\mathrm{k}_{1}=1 / \Delta \mathrm{t}$ as a special case.

The error $\mathrm{x}$ is eliminated in equation (14); for the calculation of $R_{\mathrm{H}_{2} \mathrm{O}}$ only $\mathrm{V}_{0}, \mathrm{Y}_{0}$ and the elimination constant $\mathrm{k}_{1}$ are needed. This is a logical loop: the elimination constant $k_{1}$ is first measured during the experiment and may not be precisely known a priori. Prior knowledge of $k_{1}$ is equivalent to an error of the measurement of zero.

Question 3: The term $\mathrm{x}$ influences the value of the first concentration as well as the elimination constant $k_{1}$. As a consequence $\Delta c_{2}$ should be influenced too.

Answer: We assumed for this calculation that the ${ }^{2} \mathrm{H}$ concentration is not correctly determined because the sample is taken before the tracer is completely distributed in body water. With this assumption the value of $\Delta c_{2}$ should not be dependent on $\Delta c_{1}$, because equilibrium will be reached correctly, but delayed. This is also the case if an error occurs during the analysis of the ${ }^{2} \mathrm{H}$ concentration of the first sample. On the other hand, both $\Delta c_{1}$ and $\Delta c_{2}$ may be involved, e.g. if the given amount of tracer is wrong which is equal to an error of $V_{0}$.

Question 4: Why didn't the authors discuss the influence of errors on distribution volume?

Answer: The unique feature of equation (4) is the partial compensation of errors of $\Delta c_{1}$. This is not true for all other parameters of the equation. As possible errors of all these parameters are transferred directly to the result of water turnover (law of distribution) we renounced discussion of this point. 


\title{
References
}

1. Lifson, N. \& Mc Clintock, R. (1966) Theory of Use of the Turnover Rates of Body Water For Measuring Energy and Material Balance. J. Theor. Biol. 12, 46-74.

2. Butte, N. F., Wong, W. W., Klein, P. D. \& Garza, C. (1991) Measurement of Milk Intake: Tracer-to-Infant Deuterium Dilution Method. Br. J. Nutr. 65, 3-14.

3. Fjeld, C. R., Brown, K. H. \& Schoeller, D. A. (1988) Validation of the Deuterium Oxide Method for Measuring Average Daily Milk Intake in Infants. Am. J. Clin. Nutr. 48, 617-679.

4. Coward, W. A., Cole, T. J., Gerber, H., Roberts, S. B. \& Fleet, I. (1982) Water Turnover and the Measurement of Milk Intake. Pflügers Arch. 393, 344-347.

5. Welle, S. (1990) Two-point vs Multipoint Sample Collection for the Analysis of Energy Expenditure by Use of the Doubly Labeled Water Method. Am. J. Clin. Nutr. 52, 1134-1138.

6. Fusch, Ch., Scharrer, B., Hungerland, E. \& Moeller, H. (1991) Water Turnover of Healthy Children. Ped. Res. 6, 639 (abstr.).

7. Fusch, Ch. \& Moeller, H. (1988) Detection of $\mathrm{D}_{2} \mathrm{O}$ Concentrations at Tracer Levels in Small Samples Obtained from Pediatric Patients. J. Clin. Chem. Clin. Biochem. 26, $715-721$.

8. Lukaski, H. C. \& Johnson, P. E. (1985) A Simple, Inexpensive Method of Determining Total Body Water Using a Tracer Dose of $\mathrm{D}_{2} \mathrm{O}$ and Infrared Absorption of Biological Fluids. Am. J. Clin. Nutr. 41, 363-370.

9. Wong, W. W., Cochran, W. J., Klish, W. J., O'Brian Smith, E., Lee, L. S. \& Klein, P. D. (1988) In Vivo Isotopefractionation Factors and the Measurement of Deuteriumand Oxygen-18-dilution Spaces from Plasma, Urine, Saliva, Respiratory Water Vapor, and Carbon Dioxide. Am. J. Clin. Nutr. 47, $1-6$.

10. Mendez, J., Prokop, E., Picon-Rategui, E., Akers, R. \& Buskirk, E. R. (1978) Total Body Water by $\mathrm{D}_{2} \mathrm{O}$ Dilution using Saliva Samples and Gas Chromatography. J. Appl. Physiol. 28, 354-357.

11. Schloerb, P. R., Friis-Hansen, B. J., Edelman, I. S., Solomon, A. K. \& Moore, F. D. (1950) Measurement of Total Body Water in Human Subjects by Deuterium Oxide Dilution. With a Consideration of the Dynamics of Deuterium Distribution. J. Clin. Invest. 29, 1296-1310.

12. Nielsen, W. C., Krzywicki, H. J., Johnson, H. L. \& Consolazio, C. F. (1971) Use and Evaluation of Gas Chromatography for Determination of Deuterium in Body Fluids. J. Appl. Physiol. 31, 957-961.

\author{
Dr. Christoph Fusch \\ Abteilung für Neonatologie \\ Univ.-Frauenspital \\ Schanzeneckstraße 1 \\ CH-3001 Bern \\ Schweiz
}

Prof. Dr. med. Hans Moeller, Dipl.-Biochem.

Univ.-Kinderklinik

Rümelinstraße $18-23$

W-7400 Tübingen

Bundesrepublik Deutschland 
